\title{
INDIGENOUS, LOCAL AND REGIONAL TRADITIONS: VIEWS FROM RITUAL AND CEREMONY
}

\author{
Peter Wong Yih Jiun* \\ Chinese Studies Research Centre, La Trobe University, \\ Bundoora, VIC 3086, Australia \\ E-mail: peter.wong@fastmail.fm
}

Published online: 15 July 2020

To cite this article: Wong, P. Y. J. 2020. Indigenous, local and regional traditions: Views from ritual and ceremony. International Journal of Asia Pacific Studies 16 (2): 1-9. https://doi.org/10.21315/ijaps2020.16.2.1

To link to this article: https://doi.org/10.21315/ijaps2020.16.2.1

\section{INTRODUCTION}

How do traditional communities of particular localities continue to survive and thrive in the face of what seems to be overwhelming pressures and influences from the outside? Apart from the various material and political challenges faced by these communities, equally challenging is the question of the survival and continuity of traditional values and worldviews - no doubt the material survival of the community is a basic need, it is the continuation of traditional culture that vivifies the heart and soul of a community. When we think about the resilience of a community, the continual viability of its culture is a crucial factor; yet, surely it is not merely a question of its preservation or conservation but one of creative adaptation.

Among all the various aspects of ensuring the viability of a culture, one that we are most concerned with is the ability and the means by which members of the community can convey their values and worldviews in a manner and form that can be understood, accepted and appreciated by both insiders and outsiders alike. To lead an outsider to appreciate the beauty and meaningfulness of one's culture is central to one's sense of dignity and selfrespect - and indeed critical to the long-term survival and vigour of one's community. 
We realise that the means for such communication of culture is multifaceted, much of which is expressed through the arts, through those which are performative, such as painting, music, dance, and the telling of stories, myths and sacred teachings, and those that are more material, such as architecture, textile, clothing and food. Apart from these, there are also expressions of culture that are more abstract, such as astronomy, medicine, laws, forms of social organisation, rituals, ceremonies and philosophy. The last item, being a reflective activity, is sometimes further away from the attention of those interested in maintaining and communicating one's own traditional culture in favour of matters more immediate or practical. But we would argue that communities ignore this aspect to their own detriment.

The disadvantage of not developing a philosophy of the local culture is that local culture itself is not immune to the pervading influence of philosophical discourses - which continue to be practised with or without the participation of local traditions. In particular, not only do philosophical understandings tend to inform views of outsiders (among whom are academics and politicians) regarding one's tradition, they can also influence how members of one's community understand themselves. This is mainly to do with the dominance of Western forms of thought in the various disciplines that are practised in academies of learning, which also inform governments.

Moreover, the very act of making observation and providing description of what seems to be even the most mundane subject (either by an outsider or a member of one's community) is imbued with conscious and unconscious philosophical assumptions (about oneself and others). Language is not philosophically neutral, particularly when a non-native language is employed in speaking about a local tradition. All translations involve some kind of interpretation. The uncritical adoption of terms and frameworks may lead to unintended distortions of the understanding of one's culture, and perhaps, the very practice of one's culture. Besides, there are deliberate manipulations of terms and language by those who are motivated by greed, power, racist sentiments and sometimes even well-intentioned missionary zeal. ${ }^{1}$

For the reasons above, it seems that there's no avoiding making philosophical assumptions when engaging in intellectual discourses especially in cross-cultural contexts. If that is indeed the case, then no matter how fraught the exercise, it seems that the attempt to be aware of the kind of framework and preconceived ideas one brings to the table would be preferable to an uncritical position that assumes values and worldviews are transparently communicated across cultural and linguistic barriers. This is despite the fact that many local traditions are unfamiliar with the practice of expressing understanding in the 
form of a sustained, abstract, second order discourse. Rather than rushing straight in, or to follow uncritically the opinions of those who do not have a good understanding of one's tradition, some communities might need to consider taking a backward step by re-examining those traditional sources that may be suitable for generating an indigenous philosophy, including other forms of non-discursive reflection that might exist within one's tradition.

We think that ritual is one of the more promising resources for developing an indigenous philosophy. As mentioned, rather than assuming that philosophy (in the form of a sustained, rational discourse) is commonly found in all cultures and traditions, ritual offers a better starting point. Although we are not specifically concerned with the analysis of rituals, we recognise that rituals encapsulate attitudes, understanding, modes of organising, values, forms of life, etc. It is through the consideration of rituals, sometimes as wholes, sometimes in terms of their specific parts, that may provide the grounding for a philosophy that is congenial to the local culture. As such, we do not consider our project as one of "uncovering" or "discovering" some underlying philosophy that is hitherto fully formed yet remains hidden; rather it is one of creative imagination in dialogue with the tradition.

This project begins with an interest in exploring and reflecting on philosophical resources available to local traditions in the Asia Pacific, as a way of articulating one's tradition's unique understanding and to learn how to accommodate and respect the diversity among the various cultures. The reason why we are concentrating on the Asia Pacific region is largely circumstantial, in that we inhabit a certain geographical location; it does not assume that we share a common understanding that is essentially Asian Pacific. The contributors of this issue live and work in this region and are members of its various cultures. Furthermore, we share in a common background as researchers in Western styled academia. While we work within the context of the academia in which our common language is English, we have not been acquainted with each other prior to this project.

Moreover, because each culture represented in this issue is at a different place in its self-understanding-depending also upon the research interests of contributors - what could be done for each would be different. Through pooling these writings from diverse places, both in culture and the stages of articulating philosophy, different approaches to articulation are required; nevertheless, we hope to learn and draw inspiration from each other. And we join with other people in our respective tradition who are similarly inclined. This highlights the intercultural aspect of this exercise and expresses an optimism: that despite our diverse cultural backgrounds, we can understand 
each other-and more importantly, we can learn to better understand. By our collaboration, we are of the view that local and indigenous traditions are not isolated and impervious to influence from the outside. In fact, they have always interacted, exchanged and traded cultural products with other communities.

On one level, as we address our own culture with the language and categories of the West, the limitations and inadequacies of our disciplines and frameworks are often painfully obvious. On another level, this project is one of self-empowerment with respect to particular communities of the region (many with a history of colonial occupation) - rather than deferring to what outsiders might say about one's tradition and practices, it is an attempt to express and communicate that which is closest to the heart and soul of one's people. While we acknowledge that our attempt is still made within the context of Western academic disciplines - this is an attempt to appropriate, and be reflective about, this form of "technology" for the use and purposes of one's own community. It is for the sake of maintaining one's cultural integrity and identity — and also, as a means of the tradition's meaningful adaptation in the changing world.

Naturally, there is a price to pay for such an attempt: distortion is inevitable due to the "medium" employed. Here, a reflection on the limits of translation is instructive. In attempting to communicate, one needs to speak in a manner that the outsider can understand. To do so effectively, one needs to understand the limits of the language one is employing. This does not necessarily lead to cynicism about the possibility of genuine communication. Rather, it can enable one to make appropriate allowances for the degree of distortion on account of the medium, ${ }^{2}$ a crucial skill for a translator. Far more perilous is the illusion that translations can be perfectly transparent. (To my mind, it is a skill that is also important for the audience, who otherwise might labour under a similar illusion of a perfect translation.) For this reason, developing a philosophy of one's tradition that is cognisant of such issues becomes necessary and critical. As mentioned previously, it is key to others' having a better understanding of one's deepest values, it is also at the same time key to developing a more articulate account of one's selfunderstanding. For what we say about ourselves to others directly affects what we understand ourselves to be. Therefore, the point of this exercise is not a rejection of academic discourses in the communication of one's tradition but an attempt to add one's voice to what has already been said, with an intention to communicate and express one's understanding about one's tradition, and contribute towards the development of a critical awareness about the issues of philosophical assumptions and frameworks. Moreover, we are also open 
to critique regarding our own tradition - we don't hold that traditional values are beyond reproach (and certainly not our articulations of them).

As the title of this issue suggests, our project is inclusive of, but not confined to, indigenous cultures. Neither does our understanding of indigeneity involve a thick understanding of the term, sometimes written with a capital "I," that seeks to identify common values or purpose among the colonised first people over the world. ${ }^{3}$ While we recognise the distinction between indigenous cultures and other traditions, we would like to be more inclusive in scope, for the reason that will be made clear presently. (We also accept the possibility of having cultures that might be at odds over historical or philosophical matters, so long as they remain open to listening to each other.)

Despite our diversity, there is one criterion that characterises our project; namely, we identify with those cultures and traditions that have been impacted by what could be called "world religions or world traditions," among which some are closely associated with colonial powers, and they have the common feature of being able to cross cultural boundaries; traditions we have in mind include Christianity, Islam, Buddhism - and Confucianism. The latter, however, is not strictly speaking a religion; perhaps it is better to refer to them as religious traditions. While maintaining that the cultures we identify with as not being a world religious tradition, we are at the same time particularly interested in seeing how the different local and indigenous traditions interact and deal with the strong influences of such world traditions. For instance, Confucianism has a strong influence on the Vietnamese, Koreans and Japanese, yet each people have their own unique experience of engaging with Confucianism. Therefore, while we don't normally associate the Vietnamese, Koreans and Japanese with being "indigenous," they are nevertheless cultures with a long history associated with particular lands, and their experiences of maintaining their own identity in the face of an outside culture, such as Confucianism, is of interest to this project. And similarly, the case of the Philippines with regard to Christianity. ${ }^{4}$

It is with the foregoing in mind that I have excluded myself from contributing a paper, being a person who does not belong to one of the indigenous or local cultures - a descendant of the Chinese diaspora and having spent half my life in Singapore and the other half in Australia-I have sought to make a contribution to this topic by way of being an instigator and facilitator of this project. My background in Confucian studies, together with an interest in religious and cultural diversity, provided me with an interest in this subject. Here I would also like to acknowledge Dr. Park So Jeong's contribution in the conception of this project; although present at our initial 
discussion in Melbourne University Australia, she was unable to contribute a paper because of work commitments.

In summary, there are three main objectives. We hope to learn how to express the ideas, values and spirit of one's tradition using the academic resources that are available to us; we seek to identify resources beyond the discursive written text in which those ideas, values and spirit could be found and re-imagined; and we are open to exploring the possibility of using conceptual frameworks which are not dominant in the modern West. Our commonality is not one of sharing in a particular worldview-i.e., it is not based on agreement upon a specific set of propositions, myths or songs, nor in the belief that such an agreement is necessarily possible or desirable; rather, it is based on our mutual recognition regarding the value of being able to express one's tradition or worldview, and the recognition of each other as fellow inquirers in this endeavour.

A brief description of the papers in this issue is as follows:

Linda Payi Ford's paper, "The Indigenous Australian Knowledge Tradition: New Ways for Old Ceremonies - A Case Study of Aboriginal Final Mortuary Ceremonial Practices in the Northern Territory," reports on an attempt to record and transmit ceremonial practices and knowledge of the Rak Mak Mak Marranungu people both for the members of the local community as well as for others from the wider community. It is also an attempt to differentiate what is shareable and what needs to be protected (kept secret) in order to honour traditional understanding that governs access to knowledge. At the same time, the paper provides an account on the attempt to develop an indigenous research methodology, inspired by a process to do with ceremonial food preparation of Mirrwana and Wurrkama, and within this framework, the further development of the Reflective Bio-ethnography workflow model to mediate the recording, analysis, comment and transmission of traditional ceremonial knowledge by means of modern digital archiving.

Justin Wejak's paper, "Beyond the Rituals: Philosophy of Marriage in Ata Baolangu of Lembata, Eastern Indonesia," through close observation and interviews of the members of the island community, reflects on the marriage rituals of the Ata Baolangu. Wejak makes the observation that for the Ata Baloangu, marriage is a central aspect to the meaning of life. He shows that the rituals reveal a complex negotiation of forging new relationships that go beyond the joining of a woman and a man; they involve relationships between clans, with the main purposes of forming alliances and producing offspring. 
Furthermore, the significance of the marriage rituals ought to be understood within the situated context of traditional custom, the teachings of the Roman Catholic Church, as well as the dynamics of the local community, wider societal expectations and practical concerns about status, material wealth and financial affordability. Wejak also examines how elements of the marriage ritual could be modified in the light of modern living, and raises questions about whether such modifications might affect the values and relationships of the community.

Vo Van Sen and Nguyen Ngoc Tho's paper, "Crossing Boundaries and State-building: Harmonisation and Tolerance in Vietnamese Religions," explores the ways by which a Vietnamese identity might be maintained within a cultural context that has to cope with the influences of many different world traditions, notably Confucianism and Buddhism in the past and Catholicism in more recent times. The authors propose that instead of attempting to maintain unity by means of creating a creed to be upheld by all, the Vietnamese have created social rituals; hence, unity is made possible through emphasis on orthopraxis. The authors contend that the creation of rituals contribute to the building of a Vietnamese social and cultural structure that mediate differences and diversity among the people; moreover, in order to foster harmony and mutual tolerance, a sense of compromise and allowance for a degree of ambiguity becomes necessary. And this is also achieved by privileging the sharing of social rituals over holding a set of common beliefs. Such a sense of unity was forged not by political agencies but by a coalition of the people, bureaucrats and elites, united by a sense of patriotism and a desire to be free of foreign aggression; all of which contributed to forming the goal of building a state.

Ranie Villaver's paper, “ $\mathrm{Li}$ 禮 and Filipino Behavioural Propriety,” discusses how a traditional resource-Filipino maxims and proverbs from the pre-hispanic era-could be helpful in resolving a problem in Confucian philosophy regarding the priority between two key Confucian terms, $l i$ (ritual and behavioural propriety) and ren (humanity). Villaver considers Confucian $l i$ under the aspect of behavioural propriety and argues that traditional values in a number of Filipino cultures can be used to affirm the view that proper behaviour is a necessary condition for achieving ren. Because of this shareability between Confucian philosophy and Filipino folk wisdom, Villaver further suggests that Confucianism might have a universal dimension that could be useful in consideration of other traditions. 


\section{NOTES}

* Peter Wong is a graduate of the Philosophy Department at the University of Hawai' $i$ at Mānoa, United States. His research interests include the religiousness of pre-Qin Confucianism, ritual studies and the philosophy of religion. He has a long association with Sophia, a journal on philosophy and traditions, as a book reviews editor among other roles. A recent publication is "A Perspective on Religious Diversity" in Considering Religions, Rights and Bioethics: For Max Charlesworth, of which he is also an editor. He currently works as a researcher at the Chinese Studies Research Centre at La Trobe University, Australia.

1 For example, when Christian missionaries and other Westerners encountered Chinese culture, the translation of tian 天 as "heaven" seems to be quite natural; tian being the Chinese term for "the heavens" or "sky," which invokes a certain sense of reverence. For Christian missionaries, such an association may seem fortuitous. But contemporary scholars such as Roger Ames and Henry Rosemont, Jr. question such a rendering because of its misleading association with images from the Judaeo Christian tradition and choose not to translate the term. See Ames and Rosemont, 1998, 46-48.

2 This draws inspiration from I. A. Richards' work on the Chinese classic, Mencius. Although Richards is concerned with the translation of classical Chinese into English, the issues he identifies about the difficulties of understanding a work in a language very different from one's own are instructive. See I. A. Richards, 1968, 201-217. See also, Peter Wong, 1998.

3 For a thick description of "indigenous" and an account of the term's history, see R. Niezen, 2003; Niezen notes, "Today the term [indigenous] is both a fragile legal concept and the indefinite, unachievable sum of the historical and personal experiences of those gathered in a room who share, at the very least, the notion that they have all been oppressed in similar ways for similar motives by similar state and corporate entities" (Niezen 2003, 4).

Apart from the foregoing, there is also a usage in Australia that involves using "Indigenous" and "Aboriginal" in capitals as a mark of respect which involves a recognition of the special position of the First Peoples in Australia. This particular usage is retained in Linda Payi Ford's paper. It is also useful to note that because the foregoing terms obscure the diversity of cultures and languages that exist among them, these terms are not normally the names the First Peoples in Australia choose to call themselves.

4 Although not represented in this issue, we also think of Thailand with respect to Buddhism, and Indonesia and Malaysia with respect to Islam.

\section{REFERENCES}

Ames, R. T. and Rosemont, H. (Trans1.). 1998. The analects of Confucius: A philosophical translation. New York: Ballantine.

Niezen, R. 2003. The origins of indigenism: Human rights and the politics of identity. Berkeley, Los Angles and London: University of California Press. 
Richards, I. A. 1968. So much nearer: Essays toward a world English. New York: Harcourt, Brace and World.

Wilson, S. 2008. Research is ceremony: Indigenous research methods. Black Point, NS, Canada: Fernwood Publishing.

Wong, P. 1998. Mencius on the mind: Experiments in multiple definition (review). China Review International 5 (2): 333-343. 